\title{
DIVERSITY-INVASIBILITY ACROSS AN EXPERIMENTAL DISTURBANCE GRADIENT IN APPALACHIAN FORESTS
}

\author{
R. Travis Belote, ${ }^{1,5}$ Robert H. Jones, ${ }^{1}$ Sharon M. Hood, ${ }^{2,3}$ and Bryan W. Wender ${ }^{2,4}$ \\ ${ }^{1}$ Department of Biological Sciences, Virginia Tech, Blacksburg, Virginia 24061 USA \\ ${ }^{2}$ Department of Forestry, Virginia Tech, Blacksburg, Virginia 24061 USA \\ ${ }^{3}$ USDA Forest Service, Rocky Mountain Research Station Fire Sciences Lab, Missoula, Montana 59808 USA \\ ${ }^{4}$ Virginia Division of Natural Heritage, Roanoke, Virginia 24019 USA
}

\begin{abstract}
Research examining the relationship between community diversity and invasions by nonnative species has raised new questions about the theory and management of biological invasions. Ecological theory predicts, and small-scale experiments confirm, lower levels of nonnative species invasion into species-rich compared to species-poor communities, but observational studies across a wider range of scales often report positive relationships between native and nonnative species richness. This paradox has been attributed to the scale dependency of diversity-invasibility relationships and to differences between experimental and observational studies. Disturbance is widely recognized as an important factor determining invasibility of communities, but few studies have investigated the relative and interactive roles of diversity and disturbance on nonnative species invasion. Here, we report how the relationship between native and nonnative plant species richness responded to an experimentally applied disturbance gradient (from no disturbance up to clearcut) in oakdominated forests. We consider whether results are consistent with various explanations of diversity-invasibility relationships including biotic resistance, resource availability, and the potential effects of scale $\left(1 \mathrm{~m}^{2}\right.$ to $\left.2 \mathrm{ha}\right)$. We found no correlation between native and nonnative species richness before disturbance except at the largest spatial scale, but a positive relationship after disturbance across scales and levels of disturbance. Post-disturbance richness of both native and nonnative species was positively correlated with disturbance intensity and with variability of residual basal area of trees. These results suggest that more nonnative plants may invade species-rich communities compared to species-poor communities following disturbance.
\end{abstract}

Key words: biotic acceptance; biotic resistance; deciduous forests; disturbance; diversity-invasibility relationships; forest management; plant invasions.

\section{INTRODUCTION}

Predicting which nonnative species will invade particular habitats is a major focus of ecologists and natural resource managers (Parker et al. 1999, Shea and Chesson 2002). Popular ecological theory has suggested that fewer species can colonize areas with higher resident species diversity, because more species occupy more niches, and thus provide greater "biotic resistance" to invasion (Elton 1959). Small-scale experiments have corroborated this prediction (Levine 2000, Naeem et al. 2000, Kennedy et al. 2002, Fargione and Tilman 2005). However, most observational studies that span a larger range of spatial scales suggest the opposite pattern is true: areas with more native species also support more nonnative species (Levine and D'Antonio 1999, Lonsdale 1999, Stohlgren et al. 1999, Levine 2000, Fridley et al. 2004).

Several hypotheses have been proposed to account for the paradox between experimental and observational

Manuscript received 21 February 2007; revised 11 May 2007; accepted 14 May 2007. Corresponding Editor: T. J. Stohlgren.

${ }^{5}$ E-mail: rtbelote@vt.edu studies (reviewed by Fridley et al. 2007), including the scale-dependent nature of diversity-invasibility relationships (Stohlgren et al. 1999, Levine 2000, Brown and Peet 2003, Fridley et al. 2004, Knight and Reich 2005), covarying extrinsic factors or favorable conditions that promote higher levels of both native and nonnative diversity (Levine and D'Antonio 1999, Naeem et al. 2000, Shea and Chesson 2002; Fig. 1A), and resource heterogeneity (Davies et al. 2005). For example, at small scales or within sites the number of individuals and their competitive interactions limit diversity of both native and nonnative species (Levine 2000), whereas, at large scales or across sites, resource heterogeneity contributes to higher native and nonnative species richness (Shea and Chesson 2002, Davies et al. 2005; Fig. 1A). Environmental factors that promote higher native diversity within sites and at both small and large scales may also promote nonnative diversity (Stachowicz and Tilman 2005): a pattern described as "the rich get richer" (Stohlgren et al. 2003; Fig. 1B). Ortega and Pearson (2005) recently suggested that positive relationships between native and nonnative species are found only in areas where "weak invaders" (e.g., noninvasive 




FIG. 1. Two conceptual models describing diversity-invasibility relationships proposed by Shea and Chesson (2002; panel A) and inspired by Stohlgren et al. (2006; panel B). Each separate line represents diversity-invasibility relationships at similar scales, within sites, or where environmental factors are similar. The top panel (A) predicts that "biotic resistance" to invasive species (i.e., leading to a negative slope) operates where biological and environmental factors (i.e., extrinsic factors) are similar, but relationships become positive when examined across sites or spatial scales. The bottom panel (B) predicts that "biotic acceptance" (i.e., the rich get richer) occurs within sites and at all spatial scales because resource availability or other extrinsic factors (e.g., disturbance) support both more native and nonnative species.

nonnative species) coexist with native species, but not where "strong invaders" (e.g., invasive nonnative species) dominate habitats.

Other hypotheses of plant invasions, while not mutually exclusive from those described above, focus more attention on disturbance and resource availability than on potential biotic resistance of species-rich communities (Hobbs and Huenneke 1992, Sher and Hyatt 1999, Davis et al. 2000, Huston 2004, Gross et al. 2005, Walker et al. 2005, Suding and Gross 2006). Davis et al. $(2000,2005)$ suggest that colonization of nonnative species occurs during times of increased resource supply or decreased resource uptake by resident species. Resource supply and uptake is often altered following disturbance (Huston 2004) because individual mortality leads to decreased uptake and increased availability of resources (Sher and Hyatt 1999). Moreover, disturbance is often proposed as an extrinsic factor contributing to diversity-invasibility relationships (Stohlgren et al. 1999, Levine 2000, Naeem et al. 2000, Brown and Peet 2003, Gilbert and Lechowicz 2005, Von Holle 2005). However, to our knowledge no studies have experimentally manipulated disturbance and compared pre-disturbance with post-disturbance diversity-invasibility patterns across various spatial scales, although the need for such studies is well recognized (Stohlgren 2002, Fridley et al. 2007).

In this study, we used data from an ongoing experiment in the southern Appalachian Mountains (USA) to assess the relationship between richness of native and nonnative plant species across an experimentally created, large-scale, disturbance gradient. Seven silvicultural disturbance treatments, representing alternative management practices, were replicated at seven oak-dominated forested sites in West Virginia and Virginia. The experimental design allowed us to test the effects of disturbance intensity on relationships between richness of native and nonnative plant species across sites and disturbance treatments, within sites and disturbance treatments, and at various spatial scales using both pre-disturbance and post-disturbance data. We could then determine if extrinsic factors caused by site differences (i.e., biotic and abiotic variability associated with geographic location) or disturbance intensity led to changes in the relationship between richness of native and nonnative species across a range of spatial scales (Naeem et al. 2000, Shea and Chesson 2002, Stohlgren et al. 2006). Shea and Chesson's (2002) model predicts negative relationships between native and nonnative species where extrinsic factors are similar (e.g., at small spatial scales or in areas of similar environmental conditions), but positive relationships across areas of differing extrinsic factors that may occur at larger spatial scales or across sites. This is illustrated in Fig. 1A where each line segment represents data from a particular community type or unique set of environmental conditions. Alternatively, the "biotic acceptance" conceptual model suggests that favorable conditions that promote high native richness of a habitat will also promote high nonnative richness within and across sites (Fig. 1B; Stohlgren 2002, 2006).

After considering these various models, we made two general predictions, each tested by a series of correlation analyses. First, when data were analyzed across all sites and disturbance treatments, we predicted an overall positive relationship between native and nonnative richness, corresponding to the general positive trends in Fig. 1A, B. Second, when data were analyzed within sites or disturbance treatments, we predicted negative relationships, represented by the negative trend for individual line segments in Fig. 1A. Further, we expected to find more negative relationships between 
native and nonnative richness at the smallest scales, where species interactions would likely be the strongest. We also investigated whether areas of higher predisturbance richness resisted invasions by nonnative species following disturbance compared to areas of lower pre-disturbance richness. All correlations and regressions were tested separately at each of three spatial scales $\left(1 \mathrm{~m}^{2}, 576 \mathrm{~m}^{2}\right.$, and $\left.2 \mathrm{ha}\right)$.

\section{Methods \\ Study sites}

Seven sites (experimental blocks) were chosen in the Valley and Ridge province and Appalachian Plateau region of southwest Virginia and northeastern West Virginia located on the Jefferson National Forest and the Westvaco Corporation's Wildlife and Ecosystem Research Forest, respectively (Appendix A: Fig. A1). Sites were selected to represent similar overstory composition and age and were dominated by Quercus spp. (red and white oaks), Acer rubrum L. (red maple), and Carya spp. (hickories). The understory at the sites is diverse with native species exceeding 700 species, including a variety of understory trees (e.g., Sassafras albidum (Nutt.) Nees, Nyssa sylvatica (Marsh.)), shrubs (e.g., Rhododendron spp., Vaccinium spp.), lianas (e.g., Smilax spp.), graminoids (e.g., Carex spp., Dichanthelium spp.), and herbaceous monocots (e.g., members of Liliaceae and Orchidaceae) and dicots (e.g., species from Asteraceae and Roseaceae). Sites were located on similar topographic positions with generally south-facing, moderate slopes $(10-40 \%)$ and intermediate elevations (600-1200 m). Soils at all sites are rocky, well drained, acidic, and derived from sandstone and shale residuum and colluvium. Precipitation is generally evenly distributed throughout the year.

At each of the seven sites, seven 2-ha experimental units (EUs) were established with no buffer between units (Appendix A: Fig. A2). Nested within each EU, three permanent $576-\mathrm{m}^{2}(24 \times 24 \mathrm{~m})$ plots were randomly arranged so that they were $23 \mathrm{~m}$ from the EU edge and were separated by an azimuth of $120^{\circ}$ from EU center. Six $1-\mathrm{m}^{2}$ subplots were nested within each 576- $\mathrm{m}^{2}$ plot (subplots were located along plot perimeters). For additional information about the sites and plot designs see Wender (2000) and Hood (2001).

\section{Disturbance treatments}

Disturbance treatments were applied to the 2-ha experimental units between 1993 and 1998, during the non-growing season. Treatments were randomly assigned to EUs within each site, and included a range of overstory removal, from clearcut $(95 \%$ basal area removed), low-leave shelterwood ( $83 \%$ basal area removed, leaving un-merchantable trees), leave-tree harvest $(74 \%$ of basal area removed leaving a few dominants), high-leave shelterwood (56\% of basal area removed to "thin" the stand), group selection ( $47 \%$ basal area removed in approximately 0.10 -ha patches), under- story herbicide (14\% of basal area removed from suppressed trees), to uncut control. During tree harvest, limbs and branches were removed from main stems and typically left on site. Control treatments were intended to represent areas that experience no disturbance related to timber harvesting. However, during treatment application of nearby sites, some minor disturbance associated with skid trails and diffuse light from adjacent treatments occurred within some uncut control EUs; however, these disturbances were mostly restricted to the edges of the EUs. The seven treatments were applied to examine the influences of alternative management strategies on multiple system components including plant and animal diversity, oak regeneration, and soil ecosystem processes. One West Virginia site did not include the low-leave shelterwood or the understory herbicide treatments; thus the experimental set-up is an unbalanced randomized block design consisting of 47 EUs.

\section{Data collection}

All data were collected one year prior to and one or two years following disturbance treatment application with the exception of one site where pre-disturbance data were collected two years prior to harvesting disturbance (Hammond et al. 1998, Wender 2000, Hood 2001). Presence of all herbaceous and woody plant species was recorded at each of the three scales (EU, plot, and subplot). Using number of species present, we generated estimates of species richness for native and nonnative species at each scale. Basal area of the EUs was estimated using individual tree diameter data, which were collected by measuring diameters at $1.4 \mathrm{~m}$ of all species greater than $5 \mathrm{~m}$ tall within each plot; these data were collected at the same time as the species richness data.

\section{Statistical analysis}

We used Pearson's correlation to investigate the relationship between native and nonnative species richness at each of the three spatial scales of sampling (2-ha EUs, $576-\mathrm{m}^{2}$ plots, and $1-\mathrm{m}^{2}$ subplots) prior to disturbance and after disturbance separately. For the two smaller scales, we averaged the richness values within experimental unit to meet the assumption of independence (i.e., they were treated as subsamples within an experimental unit). First, we used the entire data set for these analyses, resulting in six correlations (pre- and post-disturbance by three scales). However, to differentiate between the alternatives illustrated in Fig. 1 , we ran separate analyses by site (seven sites, each with the same six correlations for a total of 42 correlations) and by treatment (seven treatments, each with six correlations for another 42 analyses). Because of the large numbers of correlations (90 in all), several significant correlations were expected by chance alone, and thus, we examined results for large changes in the number of significant correlations, and for differences in 
negative vs. positive correlations (the latter is especially useful to examine hypotheses in Fig. 1).

To test the prediction that greater species richness leads to greater resistance to invasion following disturbance, we regressed the change in native, nonnative, and total richness (i.e., difference between pre-disturbance and post-disturbance richness) on total pre-disturbance richness at the three spatial scales; thus, we performed nine separate analyses. Because disturbance intensity (percentage of basal area removed) strongly influenced native and nonnative post-disturbance richness, we investigated both main and interactive effects of total pre-disturbance richness and percentage of basal area removed in the regression model (PROG GLM in SAS 9.1 [SAS Institute, Cary, North Carolina, USA]):

$$
\begin{aligned}
\Delta \text { richness }= & \mu+\text { pre-richness }+ \text { disturbance } \\
& + \text { pre-richness } \times \text { disturbance }+\varepsilon
\end{aligned}
$$

where $\Delta$ richness is either the change in total, native, or nonnative richness at each scale (using a separate model for each category and scale); $\mu$ is the overall mean change in richness; pre-richness is the total (native and nonnative species combined) richness before disturbance treatments were applied; disturbance is the percentage of basal area removed; and $\varepsilon$ is the residual variation.

To test whether results were consistent with hypothesized influences of resource availability and resource heterogeneity, we conducted two sets of simple linear regressions. First, we regressed experimental unit species richness on disturbance intensity (percentage of basal area removed) for native and nonnative species separately, at all three scales (six regressions where $N=47$ for each regression). These regressions provide a test of the favorable-conditions hypothesis (Levine and D'Antonio 1999), because resources made available by canopy disturbance would allow both native and nonnative species to colonize areas similarly. We also regressed richness of native and nonnative species at each spatial scale on the coefficient of variation $(\mathrm{CV})$ of postdisturbance basal area to investigate the potential importance of resource heterogeneity (patchiness of residual trees left following disturbance) in determining diversity-invasibility relationships (Davies et al. 2005). Residuals of all data were analyzed for homogeneity of variance; those not meeting this assumption were log or arcsine square-root transformed prior to analysis as appropriate.

\section{RESULTS}

No relationship between native and nonnative plant species richness was detected prior to disturbance across sites and disturbance treatments except at the largest spatial scale where a positive relationship was observed (Fig. 2). After the disturbance gradient was applied strong positive correlations developed between native and nonnative richness across sites and disturbance treatments at all scales. When we examined data within sites (with disturbance treatments pooled within site), few significant relationships between native and nonnative species richness were observed before disturbance, except at the two West Virginia sites at the largest spatial scale where the relationship was negative at one site and positive at the other (Table 1). Post-disturbance relationships between native and nonnative species within site were either positive or nonsignificant depending on scale and site. When we examined data within disturbance treatments (sites pooled within treatment), again pre-disturbance relationships were weak; only one negative correlation between native and nonnative species richness was detected (Table 2). However, after disturbance positive correlations between native and nonnative richness were commonly found at the largest spatial scale, and in the most disturbed treatments even at the smallest spatial scale. In sum, whether we examined the full data set or analyzed within sites or within treatments, pre-disturbance relationships between native and nonnative richness were weak and post-disturbance relationships tended to be strongly positive.

Change in total and native species richness did not depend on pre-disturbance species richness at any scale (Table 3), but percentage of basal area removed did explain the increase in total, native, and nonnative species richness at all scales. However, change in nonnative species was marginally dependent $(P=0.06)$ on an interaction between pre-disturbance total richness (native and nonnatives) and percentage of basal area removed at the intermediate scale $\left(576-\mathrm{m}^{2}\right.$ plot) (Table $3)$. Specifically, at this intermediate spatial scale more nonnative species colonized areas where pre-disturbance species richness was high and disturbance was most intense than areas where pre-disturbance richness and disturbance intensity were lower (Fig. 3).

Disturbance intensity (percentage of basal area removed) and resulting habitat heterogeneity (CV of residual basal area) were related to the patterns of increased richness. Richness of both native and nonnative species was positively related to percentage of basal area removed at all scales (Fig. 4, Table 4). Both were also positively correlated with coefficient of variation (i.e., habitat heterogeneity) of basal area following disturbance (Fig. 4). Nonnative species richness increased more dramatically (i.e., had a steeper slope) than native species with increasing disturbance intensity and variability of remaining basal area at all scales. Total basal area removed and variability of residual basal area, however, were positively correlated $(r=0.54 ; P<$ 0.0001 ), so it is difficult to determine the independent influence that each of these two factors may have on the post-harvest increase in species richness.

\section{Discussion}

Consistent with our first prediction and other observational studies (Stohlgren 2002), our study suggests that the relationship between native and nonnative species richness was generally positive within 

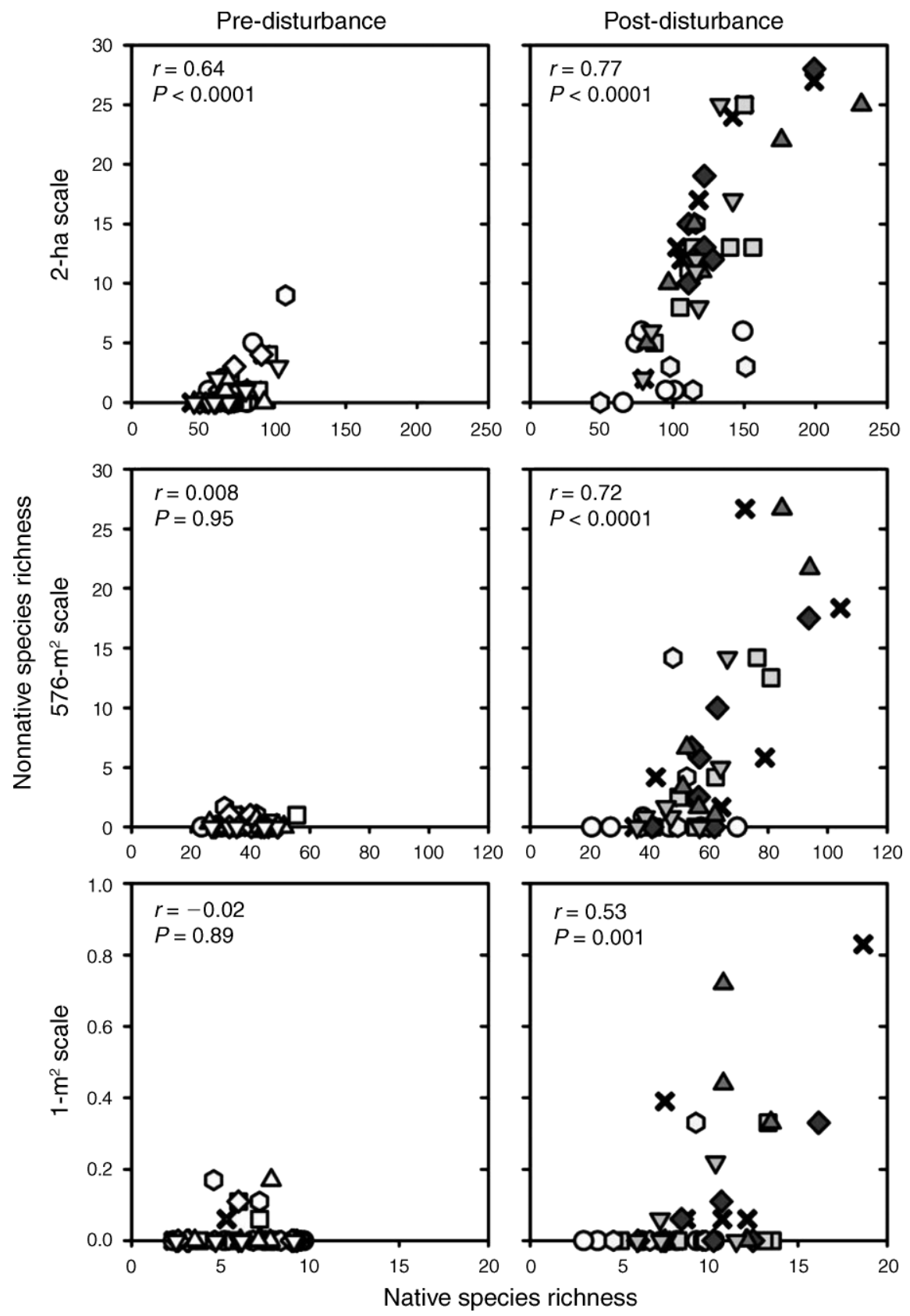

FIG. 2. Relationship between native and nonnative species richness at three spatial scales $\left(2 \mathrm{ha}, 576 \mathrm{~m}^{2}\right.$, and $\left.1 \mathrm{~m}^{2}\right)$ before disturbance and following disturbance. Pearson's correlation coefficient and associated $P$ values are provided and indicate correlation between native and nonnative species richness across disturbance treatments and sites. Symbols are open in left-hand pre-disturbance columns and solid in right-hand post-disturbance columns to indicate seven disturbance treatments (circles, control; hexagons, understory herbicide; squares, group selection; down-pointing triangles, high-leave shelterwood (i.e., more residual trees left on site); diamonds, leave-tree harvest; up-pointing triangles, low-leave shelterwood (i.e., fewer residual trees left on site); and $\times$, clearcut). Correlation coefficients for within-treatment analyses are in Table 2 .

oak-dominated forest systems when data were combined across sites and disturbance treatments. However, the presence and strength of the positive relationships depended on disturbance intensity and scale. More intense tree harvesting disturbance increased richness of both native and nonnative species, which explains the positive correlation between native and nonnative species following harvesting disturbance. As recognized by Fridley et al. $(2004,2007)$ and Stachowicz and Tilman (2005), the relationship between native and nonnative species richness is not necessarily causal but results from each group responding similarly to extrinsic 
TABLE 1. Relationship between native and nonnative species richness (Pearson's correlation coefficient and associated $P$ value) at seven sites (disturbance treatments pooled within site) in oak-dominated forests within the southern Appalachian Mountains before silvicultural disturbance and post-disturbance at three spatial scales.

\begin{tabular}{|c|c|c|c|c|c|c|c|c|c|c|c|c|}
\hline \multirow[b]{3}{*}{ Site } & \multicolumn{6}{|c|}{ Pre-disturbance } & \multicolumn{6}{|c|}{ Post-disturbance } \\
\hline & \multicolumn{2}{|c|}{2 ha } & \multicolumn{2}{|c|}{$576 \mathrm{~m}^{2}$} & \multicolumn{2}{|c|}{$1 \mathrm{~m}^{2}$} & \multicolumn{2}{|c|}{2 ha } & \multicolumn{2}{|c|}{$576 \mathrm{~m}^{2}$} & \multicolumn{2}{|c|}{$1 \mathrm{~m}^{2}$} \\
\hline & $r$ & $P$ & $r$ & $P$ & $r$ & $P$ & $r$ & $P$ & $r$ & $P$ & $r$ & $P$ \\
\hline $\mathrm{BB} 1$ & 0.44 & 0.32 & -0.003 & 0.99 & 0.011 & 0.98 & 0.85 & 0.01 & 0.91 & 0.005 & 0.91 & 0.004 \\
\hline BB2 & -0.04 & 0.93 & 0.46 & 0.29 & 0.39 & 0.38 & 0.77 & 0.04 & 0.88 & 0.009 & 0.77 & 0.04 \\
\hline CL1 1 & $\dagger$ & & -0.11 & 0.82 & $\dagger$ & & 0.95 & 0.001 & 0.61 & 0.15 & -0.25 & 0.58 \\
\hline CL2 & 0.16 & 0.74 & 0.32 & 0.47 & $\dagger$ & & 0.99 & $<0.0001$ & 0.77 & 0.04 & 0.37 & 0.41 \\
\hline $\mathrm{NC}$ & 0.33 & 0.47 & 0.39 & 0.39 & -0.62 & 0.14 & 0.95 & 0.001 & 0.85 & 0.01 & 0.36 & 0.43 \\
\hline WV1 & -0.95 & 0.01 & 0.13 & 0.83 & 0.25 & 0.68 & 0.85 & 0.06 & 0.48 & 0.41 & 0.52 & 0.36 \\
\hline WV2 & 0.96 & 0.0005 & 0.69 & 0.08 & + & & 0.91 & 0.004 & 0.80 & 0.03 & 0.72 & 0.06 \\
\hline
\end{tabular}

Notes: Site codes are: BB1, Blacksburg District site 1; BB2, Blacksburg District site 2; CL1, Clinch District site 1; CL2, Clinch District site 2; NC, New Castle District site; WV1, Westvaco Corporation site 1; WV2, Westvaco Corporation site 2 . $N=7$ experimental units for all correlations, except WV1 where $N=5$ for each correlation.

$\dagger$ No nonnative species present.

environmental factors (Naeem et al. 2000), in this case a disturbance gradient.

Our second prediction that relationships between native and nonnative richness would be negative within sites or treatments was not supported. Theory suggests that negative relationships between native and nonnative richness are more likely observed within sites or within treatments where intrinsic factors such as competition for resources by existing vegetation would limit invasibility but where extrinsic factors are relatively constant throughout the community (Fig. 1A; Shea and Chesson 2002). However, even when examining data within sites and disturbance treatments, few negative relationships were detected. We also predicted that the relationship between native and nonnative species would be negative at small scales where intrinsic factors are more likely to control diversity and invasibility than at larger scales where extrinsic factors more likely produce positive diversity-invasibility relationships (Fridley et al. 2004). However, we found no relationships between native and nonnative richness at the $1-\mathrm{m}^{2}$ scale before disturbance and a positive relationship across sites and disturbance treatments and within the clearcut treatments following disturbance. This pattern suggests that while resident species may resist colonization of nonnative species in some systems on small spatial scales (Levine 2000, Dukes 2001, Kennedy et al. 2002), coexistence mechanisms between native and nonnative species may operate at least temporarily following disturbance even at the smallest spatial scale in areas of intense disturbance.

Biological resistance to colonization by both native and nonnative species may have occurred in this system prior to disturbance, and this may explain the relatively low number of nonnatives observed before forests were harvested. However, it appears that any biological resistance that may occur before disturbance is overwhelmed by canopy removal disturbance and the introductions or emergence of propagules following disturbance. Von Holle and Simberloff (2005) investigated nonnative plant establishment in experimental plant communities located near the sites described in this

TABLE 2. Relationship between native and nonnative species richness (Pearson's correlation coefficient and associated $P$ value) within plots receiving seven silvicultural disturbance treatments in oak-dominated forests within the southern Appalachian Mountains before silvicultural disturbance and post-disturbance at three spatial scales (sites pooled within disturbance treatments).

\begin{tabular}{|c|c|c|c|c|c|c|c|c|c|c|c|c|}
\hline \multirow[b]{3}{*}{ Treatment } & \multicolumn{6}{|c|}{ Pre-disturbance } & \multicolumn{6}{|c|}{ Post-disturbance } \\
\hline & \multicolumn{2}{|c|}{2 ha } & \multicolumn{2}{|c|}{$576 \mathrm{~m}^{2}$} & \multicolumn{2}{|c|}{$1 \mathrm{~m}^{2}$} & \multicolumn{2}{|c|}{2 ha } & \multicolumn{2}{|c|}{$576 \mathrm{~m}^{2}$} & \multicolumn{2}{|c|}{$1 \mathrm{~m}^{2}$} \\
\hline & $r$ & $P$ & $r$ & $P$ & $r$ & $P$ & $r$ & $P$ & $r$ & $P$ & $r$ & $P$ \\
\hline $\mathrm{CON}$ & 0.31 & 0.49 & 0.17 & 0.71 & $\dagger$ & & 0.44 & 0.32 & -0.15 & 0.74 & $\dagger$ & \\
\hline $\mathrm{HB}$ & 0.92 & 0.003 & -0.82 & 0.05 & -0.32 & 0.53 & 0.28 & 0.53 & 0.32 & 0.53 & $\dagger$ & \\
\hline GR & 0.78 & 0.04 & 0.34 & 0.44 & -0.14 & 0.76 & 0.75 & 0.05 & 0.86 & 0.012 & 0.45 & 0.31 \\
\hline SW50/60 & 0.76 & 0.04 & $\dagger$ & & $\dagger$ & & 0.84 & 0.017 & 0.72 & 0.066 & 0.43 & 0.34 \\
\hline LV & 0.51 & 0.30 & -0.29 & 0.54 & -0.04 & 0.93 & 0.91 & 0.01 & 0.48 & 0.27 & 0.47 & 0.28 \\
\hline SW20/30 & 0.14 & 0.79 & -0.19 & 0.72 & 0.37 & 0.47 & 0.95 & 0.004 & 0.89 & 0.018 & 0.12 & 0.81 \\
\hline $\mathrm{CC}$ & 0.75 & 0.05 & 0.23 & 0.63 & -0.14 & 0.76 & 0.91 & 0.004 & 0.64 & 0.12 & 0.76 & 0.047 \\
\hline
\end{tabular}

Notes: Treatment abbreviations are: $\mathrm{CON}$, uncut control; HB, understory herbicide; GR, group selection; SW50/60, high-leave shelterwood (i.e., more residual trees left on site); LV, leave-tree harvest; SW20/30, low-leave shelterwood (i.e., fewer residual trees left on site); CC, clearcut. See Methods for description of treatments. $N=7$ experimental units for all correlations, except SW20/30 and $\mathrm{HB}$, where $N=6$ for each correlation.

$\dagger$ No nonnative species present. 
TABLE 3. $P$ values from general linear model investigating the effects of total species richness before disturbance, percentage of basal area removed, and their interaction on the change (difference between pre- and post-disturbance richness) in total, native, and nonnative species richness at three spatial scales.

\begin{tabular}{llccc}
\hline \hline Scale & $\begin{array}{c}\text { Change in } \\
\text { richness }\end{array}$ & $\begin{array}{c}\text { Pre-disturbance } \\
\text { total richness }\end{array}$ & $\begin{array}{c}\text { Percentage of } \\
\text { basal area } \\
\text { removed }\end{array}$ & Interaction \\
\hline $2 \mathrm{ha}$ & total & 0.35 & 0.002 & 0.94 \\
& native & 0.24 & 0.008 & 0.99 \\
$576 \mathrm{~m}^{2}$ & nonnative & 0.72 & $<0.0001$ & 0.69 \\
& total & 0.13 & $<0.0001$ & 0.44 \\
& native & 0.14 & $<0.0001$ & 0.63 \\
$\mathrm{I} \mathrm{m}^{2}$ & nonnative & 0.15 & 0.0016 & 0.06 \\
& total & 0.53 & $<0.0001$ & 0.28 \\
& native & 0.48 & $<0.0001$ & 0.29 \\
& nonnative & 0.65 & 0.006 & 0.47 \\
\hline
\end{tabular}

Note: $N=47$ experimental units for each model.

study and suggested that propagule pressure of invaders can overcome biological resistance of recipient communities as well as the environmental resistance of stressful abiotic conditions. In our study, changes in total, native, or nonnative species depended on disturbance intensity and not on total pre-disturbance richness at the largest and smallest spatial scales. However, at intermediate spatial scales, sites with higher pre-disturbance richness tended to be colonized by more nonnative species especially in areas where disturbance was most intense. The results of this study support the "biotic acceptance" (i.e., the rich get richer; Stohlgren et al. 2003; Fig. 1B) rather than "biotic resistance" model of species invasions (Levine et al. 2004, Von Holle 2005); i.e., areas that support more natives are also more easily invaded by nonnative species, especially following disturbance.

While we have no direct environmental measures for resource-based mechanisms, tree harvesting likely increased light and nutrient availability, soil temperature, and soil moisture by reduced evapotranspiration (Johnson et al. 2002). Harvesting disturbance thus allowed for either more native and nonnative propagules to enter

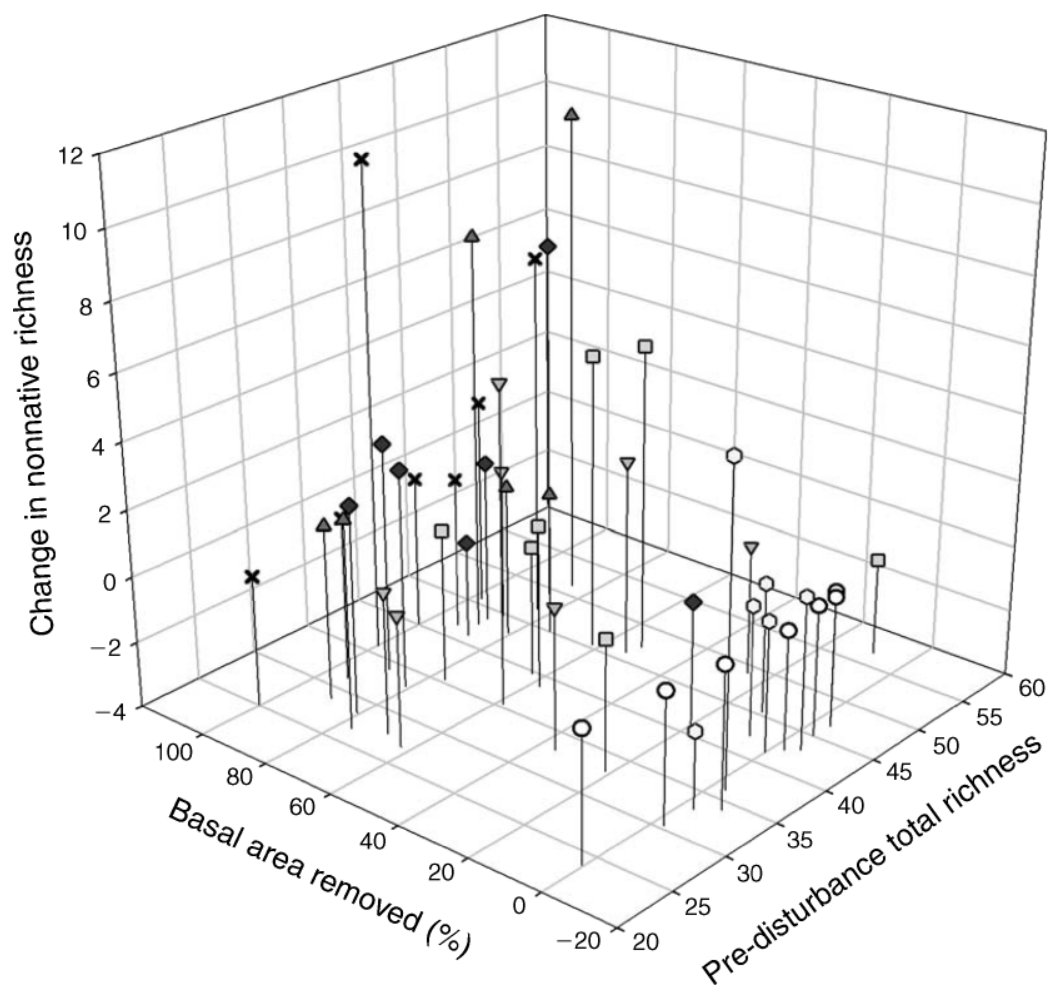

FIG. 3. Relationships between pre-disturbance total diversity (sum of native and nonnative species), percentage of basal area removed, and increase in number of nonnative species at the $576-\mathrm{m}^{2}$ scale (pre-disturbance richness $\times$ percentage of basal area removed interaction, $P=0.06$ ). Symbols indicate the seven disturbance treatments, as in Fig. 2. 

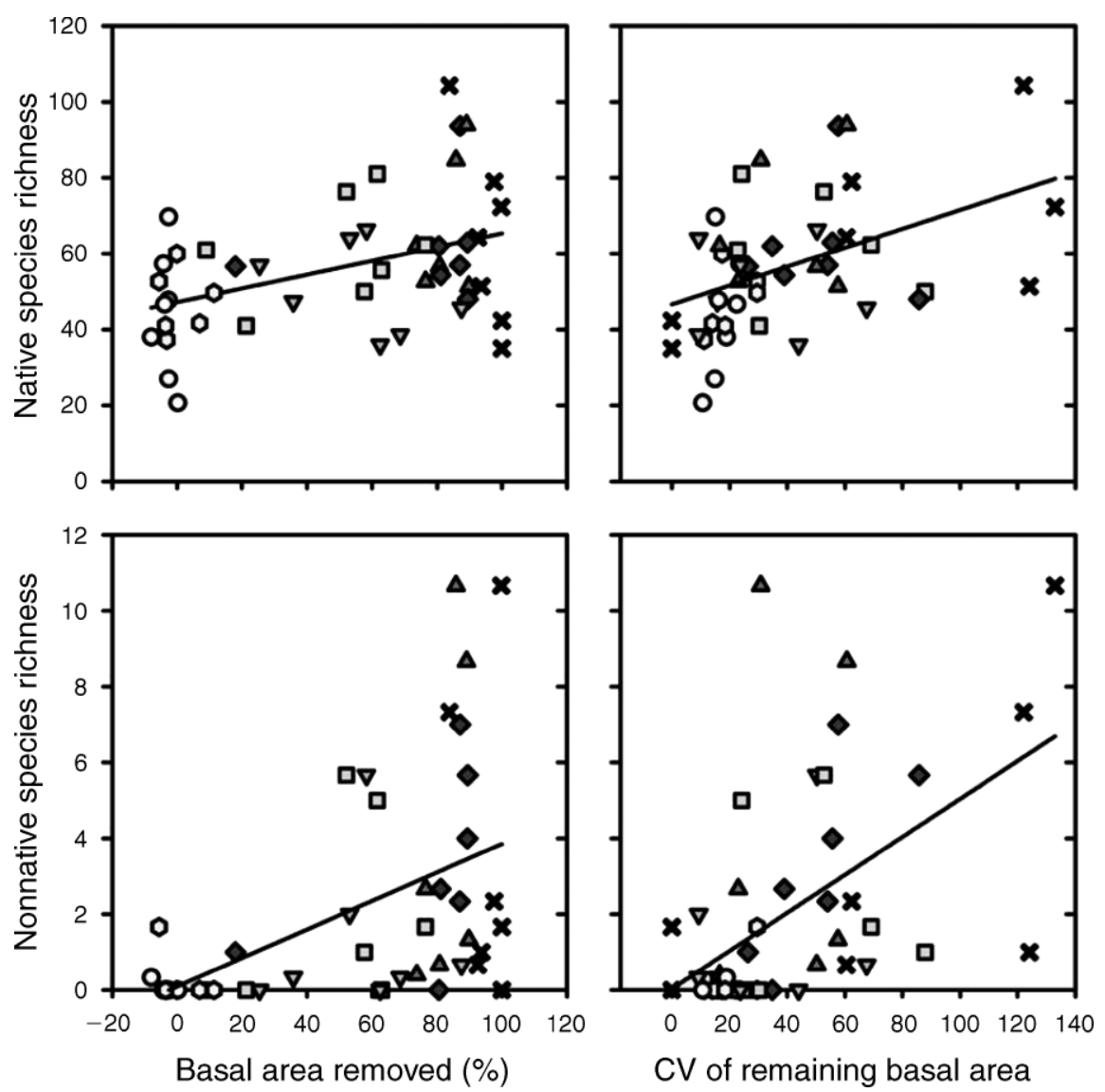

FIG. 4. Relationships between native and nonnative species richness and (left-hand panels) the percentage of basal area removed and (right-hand panels) the coefficient of variation (CV) of remaining basal area following disturbance at the $576-\mathrm{m}^{2}$ scale. Symbols are the same as in Fig. 2. Slope, $R^{2}$, and $P$ values for regressions are given in Table 4.

sites, existing propagules to germinate, or both. Brown and Peet (2003) observed similar positive relationships between native and nonnative species richness in riparian areas of the southern Appalachians with higher flooding frequency, a pattern attributed to propagule pressure from both native and nonnatives species.

The disturbance treatments also resulted in patchiness of residual tree basal area (our measure of habitat heterogeneity). Davies et al. (2005) recently presented a positive relationship between variance of soil depth and native and exotic diversity and showed that the spatial heterogeneity, but not favorable conditions hypothesis, explains the positive relationship between native and nonnative plants. Our results show that the favorable conditions hypothesis (Levine and D'Antonio 1999) and resource heterogeneity hypothesis (Davies et al. 2005) may not be mutually exclusive. Treatments with greater variability in residual basal area supported more native and nonnative species, but more intense disturbance also resulted in more native and nonnative species.

Nonnative species had greater rates of colonization (proportional to richness prior to disturbance) following

TABLE 4. Slope, $R^{2}$, and $P$ value from regression analysis relating native and nonnative richness to percentage of basal area removed and coefficient of variation of remaining basal area at three spatial scales and across sites and disturbance treatments.

\begin{tabular}{|c|c|c|c|c|c|c|c|c|c|c|c|c|}
\hline \multirow[b]{3}{*}{ Scale } & \multicolumn{6}{|c|}{ Percentage of basal area removed } & \multicolumn{6}{|c|}{$\mathrm{CV}$ of remaining basal area } \\
\hline & \multicolumn{3}{|c|}{ Native } & \multicolumn{3}{|c|}{ Nonnative } & \multicolumn{3}{|c|}{ Native } & \multicolumn{3}{|c|}{ Nonnative } \\
\hline & Slope & $R^{2}$ & $P$ & Slope & $R^{2}$ & $P$ & Slope & $R^{2}$ & $P$ & Slope & $R^{2}$ & $P$ \\
\hline 2 ha & 0.37 & 0.11 & 0.02 & 2. & 0.32 & $<0.0001$ & 0.33 & 0.14 & 0.01 & 2.1 & 0.27 & 0.0002 \\
\hline $576 \mathrm{~m}^{2}$ & 0.93 & 0.17 & 0.004 & 6.8 & 0.25 & 0.0003 & 0.83 & 0.21 & 0.001 & 5.8 & 0.19 & 0.017 \\
\hline $1 \mathrm{~m}^{2}$ & 5.36 & 0.18 & 0.003 & 81.85 & 0.16 & 0.006 & 3.07 & 0.09 & 0.04 & 69.45 & 0.18 & 0.003 \\
\hline
\end{tabular}

Notes: $N=47$ experimental units for each model. Fig. 3 shows data from the $576-\mathrm{m}^{2}$ scale. 
canopy disturbance, which may be attributed to the introduction of nonnative species from nearby species pools or through deliberate or accidental introduction of propagules for management purposes. Skid trails (paths used by logging machinery) were seeded with a nonnative species (Festuca arundinacea Schreb.) to reduce soil erosion, and it is unknown if other species were accidentally or intentionally included during seeding. However, most plots and subplots were located outside of these skid trails.

The lack of notoriously "strong" invading species (i.e., nonnative species that can dominate habitats) may also explain why we found positive relationships between native and nonnative species invasion. Ortega and Pearson (2005) suggested that in cases where negative relationships are observed, the pattern is not driven by biotic resistance, but by strong invaders excluding native species in some systems. The increase in both native and nonnative richness following disturbance was primarily the result of the establishment of herbaceous species, most of which are "weak" invaders (see Appendix B for list of nonnative species found at each site). However, some nonnatives that invaded the sites following disturbance are considered "strong" invaders, but the duration of time since arrival in this study limits our ability to investigate their spread and impact. We will continue to monitor these sites to determine the persistence and potential effects of the strong invasive species on native diversity and composition.

\section{Conclusions}

The importance of disturbance in plant invasions has been widely recognized (Hobbs and Huenneke 1992, Davis et al. 2000, Huston 2004), and disturbance appears to be a significant extrinsic factor that results in positive relationships between native and nonnative diversity, at least at large scales of observation (Fridley et al. 2007). Even at smaller spatial scales, where biotic resistance related to species richness is predicted to have the strongest influence on the relationship between native and nonnative species richness, we found little or no evidence to support resistance by native species richness on nonnative species invasion. Overall, therefore, hypotheses based on resource availability and disturbance (Fig. 1B) appear to better fit our results than those based on biological resistance (Fig. 1A). Our results show that both native and nonnative species colonize disturbed areas leading to positive correlations between native richness and nonnative richness. Future monitoring will investigate (1) which nonnative species persist and spread and (2) how patterns of native and nonnative richness relationships change during forest aggradation and development.

\section{ACKNOWLEDGMENTS}

We are grateful to Tom Wieboldt for providing taxonomic identification throughout the study. David W. Smith and Shep Zedaker initiated the project and directed experimental design and data collection; to them we are grateful. David Loftis provided funding for project initiation under USDA-NRI grant No. 9503196. Tom Fox and Carola Haas provided guidance throughout experimental setup and data collection. Thanks to Jason Fridley, Erik Nilsen, Betsy Von Holle, Dan Simberloff, and two anonymous reviewers for providing helpful comments and suggestions. We are thankful for Meral Jackson, Dan Hammond, and many undergraduate assistants for setting up field sites and collecting data. USDA-NRI grant No. 200535101-15363 funded data analysis and manuscript preparation.

\section{Literature Cited}

Brown, R. L., and R. K. Peet. 2003. Diversity and invasibility of southern Appalachian plant communities. Ecology 84:3239.

Davies, K. F., P. Chesson, S. Harrison, B. D. Inouye, B. A. Melbourne, and K. J. Rice. 2005. Spatial heterogeneity explains the scale dependence of the native-exotic diversity relationship. Ecology 86:1602-1610.

Davis, M. A., J. P. Grime, and K. Thompson. 2000. Fluctuating resources in plant communities: a general theory of invasibility. Journal of Ecology 88:528-536.

Davis, M. A., K. Thompson, and J. P. Grime. 2005. Invasibility: the local mechanism driving community assembly and species diversity. Ecography 28:696-704.

Dukes, J. S. 2001. Biodiversity and invasibility in grassland microcosms. Oecologia 126:563-568.

Elton, C. S. 1959. The ecology of invasions by animals and plants. The University of Chicago Press, Chicago, Illinois, USA.

Fargione, J. E., and D. Tilman. 2005. Diversity decreases invasion via both sampling and complementarity effects. Ecology Letters 8:604-611.

Fridley, J. D., R. L. Brown, and J. F. Bruno. 2004. Null models of species invasion and scale-dependent patterns of native and exotic species richness. Ecology 85:3215-3222.

Fridley, J. D., J. J. Stachowicz, S. Naeem, D. F. Sax, E. W. Seabloom, M. D. Smith, T. J. Stohlgren, D. Tilman, and B. Von Holle. 2007. The invasion paradox: reconciling pattern and process in species invasions. Ecology 88:3-17.

Gilbert, B., and M. J. Lechowicz. 2005. Invasibility and abiotic gradients: the positive correlation between native and exotic plant diversity. Ecology 86:1848-1855.

Gross, K. L., G. G. Mittelbach, and H. L. Reynolds. 2005. Grassland invasibility and diversity: responses to nutrients, seed input, and disturbance. Ecology 86:476-486.

Hammond, D. N., D. W. Smith, S. M. Zedaker, D. K. Wright, and J. W. Thompson. 1998. Floral diversity following harvest on southern Appalachian mixed oak sites. Pages 461-465 in Proceedings of the Ninth Southern Biennial Silvicultural Research Conference. General Technical Report SRS-20. USDA Forest Service, Asheville, North Carolina, USA.

Hobbs, R. J., and L. F. Huenneke. 1992. Disturbance, diversity, and invasion: implications for conservation. Conservation Biology 6:324-337.

Hood, S. M. 2001. Vegetation responses to seven silvicultural treatments in the southern Appalachians one year after harvesting. Thesis. Virginia Tech, Blacksburg, Virginia, USA.

Huston, M. A. 2004. Management strategies for plant invasions: manipulating productivity, disturbance, and competition. Diversity and Distributions 10:167-178.

Johnson, P. S., S. R. Shifley, and R. Rogers. 2002. The ecology and silviculture of oaks. CABI Publishing, Cambridge, Massachusetts, USA.

Kennedy, T. A., S. Naeem, K. M. Howe, J. M. H. Knops, D. Tilman, and P. Reich. 2002. Biodiversity as a barrier to ecological invasion. Nature 417:636-638.

Knight, K. S., and P. B. Reich. 2005. Opposite relationships between invasibility and native species richness at patch versus landscape scales. Oikos 109:81-88. 
Levine, J. M. 2000. Species diversity and biological invasions: relating local process to community pattern. Science $288: 852$ 854.

Levine, J. M., P. B. Adler, and S. G. Yelenik. 2004. A metaanalysis of biotic resistance to exotic invasions. Ecology Letters 7:975-989.

Levine, J. M., and C. M. D'Antonio. 1999. Elton revisited: a review of evidence linking diversity and invasibility. Oikos $87: 15-26$.

Lonsdale, W. M. 1999. Global patterns of plant invasions and the concept of invasibility. Ecology 80:1522-1536.

Naeem, S., J. M. H. Knops, D. Tilman, K. M. Howe, T. Kennedy, and S. Gale. 2000. Plant diversity increases resistance to invasion in the absence of covarying extrinsic factors. Oikos 91:97-108.

Ortega, Y. K., and D. E. Pearson. 2005. Weak vs. strong invaders of natural plant communities: assessing invasibility and impact. Ecological Applications 15:651-661.

Parker, I. M., D. Simberloff, W. M. Lonsdale, K. Goodell, M. Wonham, P. M. Kareiva, M. H. Williamson, B. V. Holle, P. B. Moyle, J. E. Byers, and L. Goldwasser. 1999. Impact: toward a framework for understanding the ecological effects of invaders. Biological Invasions 1:3-19.

Shea, K., and P. Chesson. 2002. Community ecology theory as a framework for biological invasions. Trends in Ecology and Evolution 17:170-176.

Sher, A. A., and L. A. Hyatt. 1999. The disturbed resource-flux invasion matrix: a new framework for patterns of plant invasion. Biological Invasions 1:107-114.

Stachowicz, J. J., and D. Tilman. 2005. Species invasions and the relationships between species diversity, community saturation, and ecosystem functioning. Pages 41-64 in D. F. Sax, J. J. Stachowicz, and S. D. Gaines, editors.
Species invasions: insights into ecology, evolution, and biogeography. Sinauer Associates, Sunderland, Massachusetts, USA.

Stohlgren, T. J. 2002. Beyond theories of plant invasions: lessons from natural landscapes. Comments on Theoretical Biology 7:355-379.

Stohlgren, T. J., D. T. Barnett, and J. T. Kartesz. 2003. The rich get richer: patterns of plant invasions in the United States. Frontiers in Ecology and the Environment 1:11-14.

Stohlgren, T. J., D. Binkley, G. W. Chong, M. A. Kalkhan, L. D. Schell, K. A. Bull, Y. Otsuki, G. Newman, M. Bashkin, and Y. Son. 1999. Exotic plant species invade hot spots of native plant diversity. Ecological Monographs 69:25-46.

Stohlgren, T. J., C. Jarnevich, G. W. Chong, and P. H. Evangelista. 2006. Scale and plant invasions: a theory of biotic acceptance. Preslia 78:405-426.

Suding, K. N., and K. L. Gross. 2006. Modifying native and exotic species richness correlations: the influence of fire and seed addition. Ecological Applications 16:1319-1326.

Von Holle, B. 2005. Biotic resistance to invader establishment of a southern Appalachian plant community is determined by environmental conditions. Journal of Ecology 93:16-26.

Von Holle, B., and D. Simberloff. 2005. Ecological resistance to biological invasion overwhelmed by invasion pressure. Ecology 86:3212-3218.

Walker, S., J. B. Wilson, and W. G. Lee. 2005. Does fluctuating resource availability increase invasibility? Evidence from field experiments in New Zealand short tussock grassland. Biological Invasions 7:195-211.

Wender, B. W. 2000. Impacts of seven silvicultural alternatives on vascular plant community composition, structure, and diversity in the Southern Appalachians. Thesis. Virginia Tech, Blacksburg, Virginia, USA.

\section{APPENDIX A}

Location of sites and diagram of nested sampling design (Ecological Archives E089-010-A1).

\section{APPENDIX B}

Nonnative plant species observed within study sites in Appalachian forests (Ecological Archives E089-010-A2). 